This item was submitted to Loughborough's Research Repository by the author.

Items in Figshare are protected by copyright, with all rights reserved, unless otherwise indicated.

\title{
A methodology for design and appraisal of surgical robotic systems
}

PLEASE CITE THE PUBLISHED VERSION

PUBLISHER

(c) Cambridge University Press

VERSION

VoR (Version of Record)

LICENCE

CC BY-NC-ND 4.0

\section{REPOSITORY RECORD}

O'Toole, Michael D., Kaddour Bouazza-Marouf, David Kerr, Mahendra Gooroochurn, and Michael Vloeberghs. 2019. "A Methodology for Design and Appraisal of Surgical Robotic Systems". figshare.

https://hdl.handle.net/2134/5887. 
This item was submitted to Loughborough's Institutional Repository (https://dspace.lboro.ac.uk/) by the author and is made available under the following Creative Commons Licence conditions.

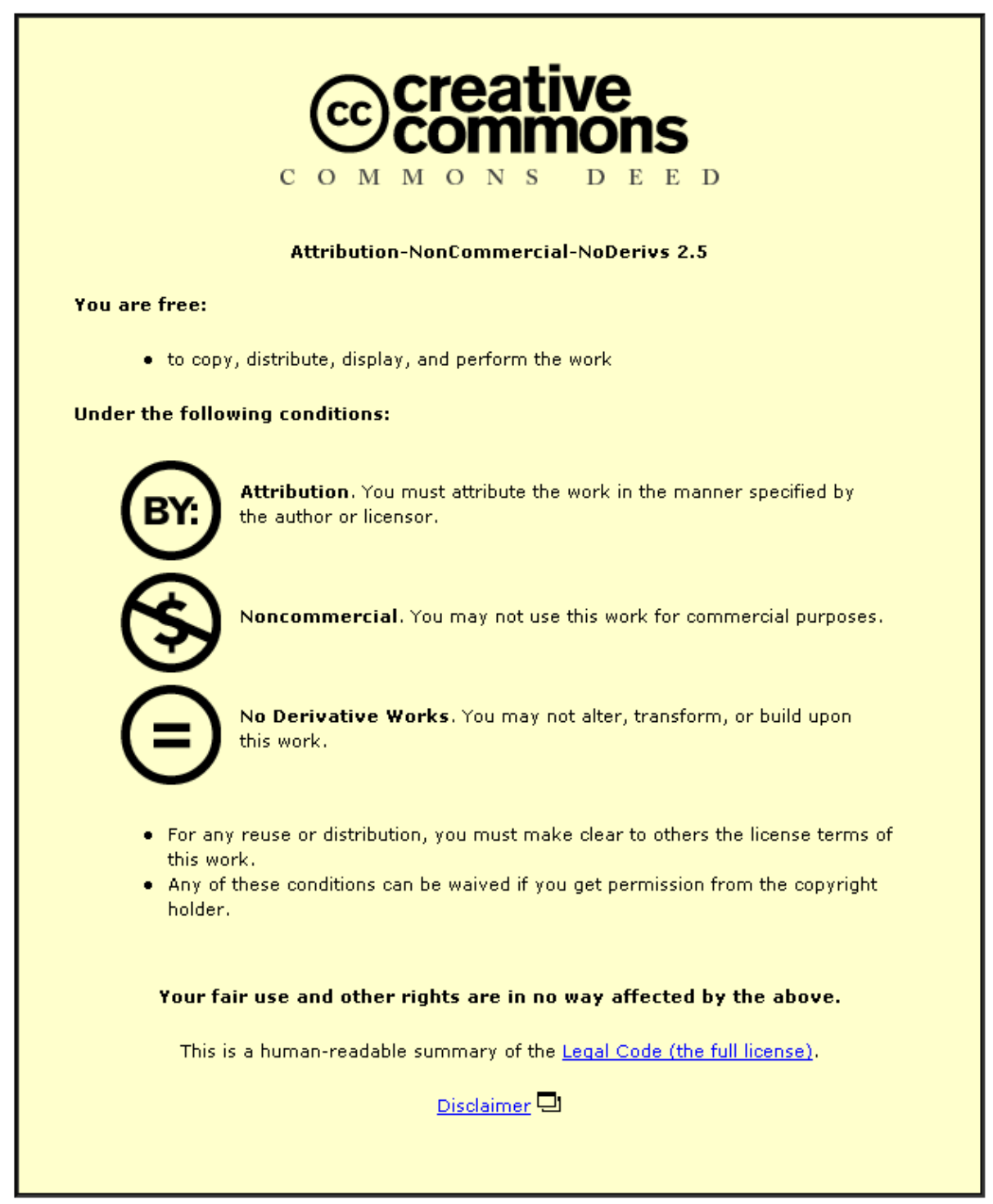

For the full text of this licence, please go to: http://creativecommons.org/licenses/by-nc-nd/2.5/ 


\title{
A methodology for design and appraisal of surgical robotic systems Michael D. O'Toole $\dagger^{*}$, Kaddour Bouazza-Marouf $\dagger$, David Kerr†, Mahendra Gooroochurn $\dagger$ and Michael Vloeberghs $\ddagger$
}

\author{
$\dagger$ Wolfson School of Mechanical and Manufacturing Engineering, Loughborough University, Loughborough, Leicestershire \\ $\ddagger$ School of Human Development, University Hospital, Queen’s Medical Centre, Nottingham
}

(Received in Final Form: October 27, 2009. First published online: December 7, 2009)

\section{SUMMARY}

Surgical robotics is a growing discipline, continuously expanding with an influx of new ideas and research. However, it is important that the development of new devices take account of past mistakes and successes. A structured approach is necessary, as with proliferation of such research, there is a danger that these lessons will be obscured, resulting in the repetition of mistakes and wasted effort and energy. There are several research paths for surgical robotics, each with different risks and opportunities and different methodologies to reach a profitable outcome. The main emphasis of this paper is on a methodology for 'applied research' in surgical robotics. The methodology sets out a hierarchy of criteria consisting of three tiers, with the most important being the bottom tier and the least being the top tier. It is argued that a robotic system must adhere to these criteria in order to achieve acceptability. Recent commercial systems are reviewed against these criteria, and are found to conform up to at least the bottom and intermediate tiers, the most important first two tiers, and thus gain some acceptability. However, the lack of conformity to the criteria in the top tier, and the inability to conclusively prove increased clinical benefit, is shown to be hampering their potential in gaining wide establishment.

\section{Introduction}

The field of surgical robotics began in the mid-1980s with the published clinical trials of Kwoh et al., ${ }^{1}$ using a PUMA 200 robot for frameless stereotaxy. Since then, research in this field has expanded considerably. There are a number of excellent reviews of surgical robotics. ${ }^{2-5}$ The most recent, by Pott et al., ${ }^{5}$ recorded 159 robotic devices in fields including medical imaging, abdominal and thoracic surgery, ENT, oral and maxillofacial surgery, neurosurgery, orthopaedics, radiosurgery, trauma surgery and urology, and yet this review was not exhaustive. Figure 1 shows the annual number of publications found using three databases - PubMed, IEEE Xplore and ISI web of knowledge under the search term 'surgical robot' and including the terms 'surgery' and 'robotic'. The results show a clear trend of increasing

\footnotetext{
* Corresponding author. E-mail: M.D.OToole@lboro.ac.uk
}

publications year on year since the opening phases of the field. It is now widely accepted that surgical robotics is a field of its own, distinct but not disconnected from the bulk of robotic research.

Despite such growth, practical implementations of the technology are rare. Few go on to clinical trials, and fewer still to any kind of commercial exploitation. There are a number of reasons, outside the roboticist's control, which can explain this discrepancy. It may, for instance, be simply a matter of timing - that the field is still reaching a stage of maturity where robotics is seen as a normal hospital tool to improve clinical outcome rather than an extravagant feature used by a few clinicians. Conservatism by the medical device industry and medical authorities and the high cost and lengthy process of approval to work on patients may also play a significant part. Although these arguments carry some weight, they are not wholly satisfactory in explaining such an acute discrepancy. Flaws in the attributes and processes by which some of the robotic systems have been realised must also be considered.

Of the clinical trials that have been undertaken, the surgeons' comments are often revealing. Complaints regarding the ease of use and steep learning curves, the practicality of having such equipment in the operating room and the high capital cost associated with such systems are frequent and are representative of the kinds of problems prohibiting widespread adoption. Furthermore, it is rare that such trials provide a clear demonstration of improved outcome over conventional surgery. This can partly be attributed to the limitations of the studies, but when considered against cost, it is a vital factor in determining value.

The direction of future applied research must lie on the foundations of the principles derived from past successes and mistakes. With the volume of research proliferating, there is real danger of this experience becoming lost under the mass of new material, resulting in the repetition of flaws and the wasting of effort and energy that could otherwise have been usefully applied. A formal and structured methodology, used to evaluate ideas and designs, is one approach to ensure that standardised best practice is shared. Thus, proposed herein is a design methodology that uses a hierarchy of criteria to act as a framework in establishing the value of a surgical robotic system. It is proposed that clinical acceptance is defined by these criteria, and that the principles outlined should be 


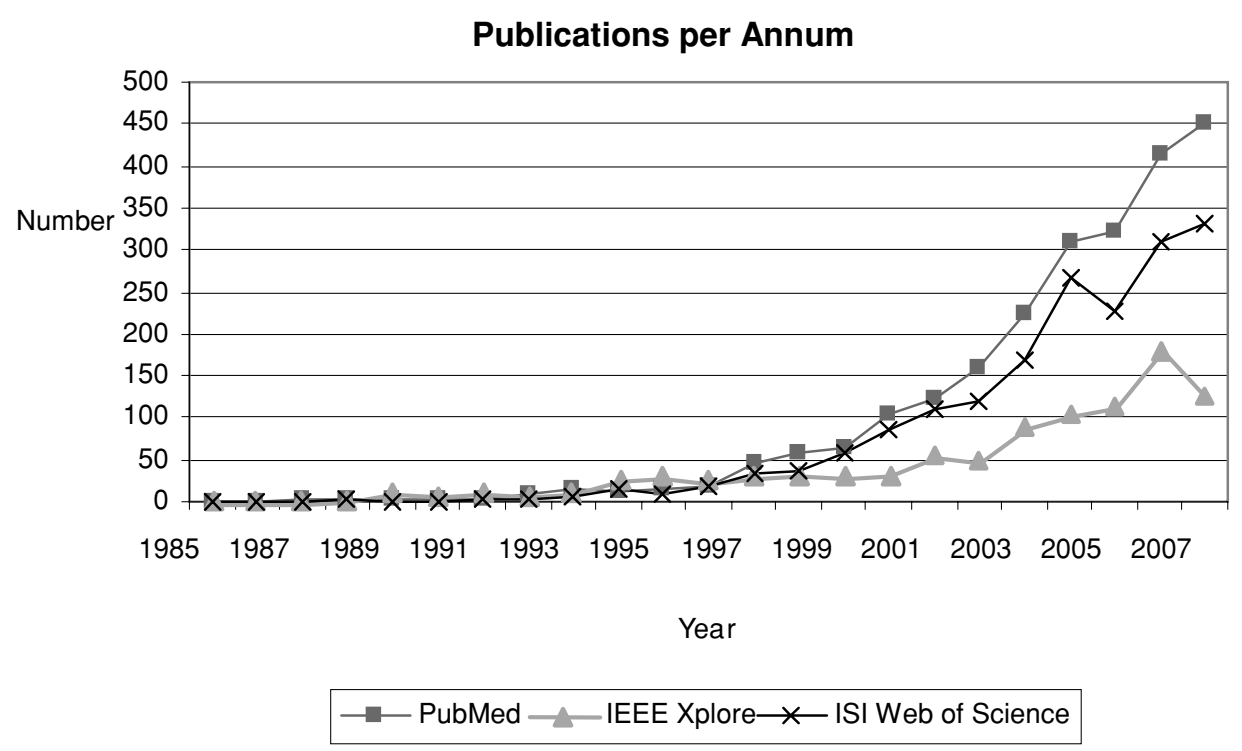

Fig. 1. Database search of surgical robot publications.

embedded in any applied research that leads to a surgical robotic system. A literature review of recent and current commercial systems is then presented in the context of this methodology and is discussed against the proposed set of criteria.

\section{Methodology for Effective Robotic Implementation in Surgery}

This methodology considers six points in evaluating a surgical robotic system: clinical need, clinical effectiveness, safety, cost, compatibility and usability. Each criterion can be considered part of a three-tiered hierarchy, in the form of an inverted triangle, that differentiates their importance, as shown in Fig. 2. Each layer must be successively 'filled' for the above to add value. Furthermore, the strength of the case to complete each criterion does not add equal value but is rather weighted according to their assigned tier - the bottom tier being the most heavily weighted and the top tier the least weighted.

The bottom tier, encompassing the criterion 'clinical need', consists of the purpose and motivation behind the project. A clinical need involves identifying the opportunity for robotic assistance in surgery based on a current deficiency. A clinical need is the most important element as it underlines the entire purpose and specification of the robotic system. The intermediate tier is related to the robotic system's performance, consisting of its clinical effectiveness and safety. These requirements must be fulfilled to give the robotic system value once a useful purpose (bottom tier) has been established. If neither can be demonstrated, then the robotic system may have a purpose but is unable to carry out the role in an acceptable way. For instance, if there is a clear role for a robotic system to improve a surgical procedure, but the design of the system means that it cannot guarantee safety, the system will be ineffectual despite having a purpose. The

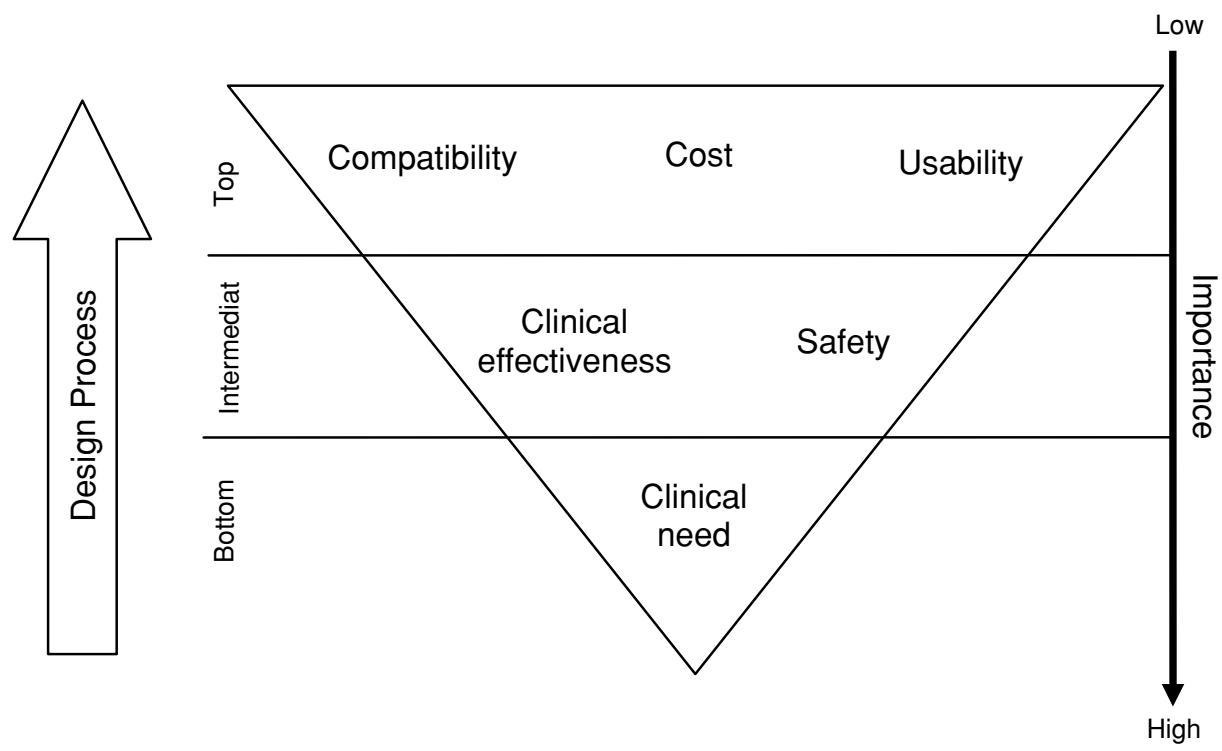

Fig. 2. A hierarchy of criteria for a surgical robotic system. 
Table I. Definition of research paths.
Surgeon-led research
Research to improve surgical techniques, or develop new techniques, using existing medical devices and technology, e.g.
-investigating the effect of the medical device on patient outcome and surgical process;
-exploring new techniques and methods for surgery by using existing devices in different ways.
Pure research
Applied research
Research into new surgical techniques that use new concepts or technology, e g. -co-development, between surgeon and engineer, of novel treatments for which the technology is intrinsic.
Applied research Solving problems and inefficiencies in current surgical practice by creating new technology, e.g.
-developing a new tool or medical device;
-equipment to streamline surgical processes and protocols.
Engineering-led research Research into finding surgical applications for new engineering concepts, e.g.
-investigating surgical applications for systems which originally had a different engineering application;
-using new algorithms, mechanisms or devices in a surgical context.

top tier considers the robotic system practicalities. None of the points in this layer would necessarily preclude a surgical robotic system if left unfulfilled; however, practically, if these are not addressed to some extent, it would be unlikely that the system achieves wide acceptance. The boundary between the intermediate tier and the top tier can be thought of as the difference between a prototype and a product.

The six criteria that form the hierarchy shown in Fig. 2 are now described. A clinical need is an established prerequisite of any surgical robotic system program. It will ultimately define the project goals and specification. Ideally, this should come on the back of a research partnership with a surgeon or other physician in the relevant area. Frequently cited areas identified as a clinical need are in bone resection tasks, minimally invasive surgery and stereotactic surgery. These areas have all spawned commercial systems. To gain acceptance, a robotic system must demonstrate competent or better clinical effectiveness relative to a conventional alternative and achieve a favourable cost-to-benefit ratio. This effectiveness can be realised in a number of ways, e.g. better success rate, reduced rate of complications, hospitalisation time and reduced blood loss. Ultimately, the clinical effectiveness of a device with respect to a conventional surgical procedure, relative to its cost, will form the basis of its acceptability to any decision-making medical authority.

A medical device is required to undergo a strict and vigorous approval process to prove its safety in practice, and surgical robotic systems are no exception. An appropriate design methodology must be used that can identify foreseeable risks and provide an appraisal of the safety controls put in place to mitigate those risks. Safety features vary from system to system. Common attributes include redundant sensors, emergency brakes, watchdog timers for control software, kinematics- and software-based restrictions, etc. Some authors have limited the role of the robotic system to increase safety, such as restricting to passive roles, e.g. using the robotic system as a tool guide. On the other hand, limiting the robotic system's role reduces the clinical benefit that it can add.

A surgical robotic system must be compatible first with its environment and then with common surgical tools. In the first instance, the environment that the system must operate in must be considered. For example, if the robotic system is required to operate in a small operating room, cluttered with instruments, it must be equally suited.
Cost refers to the cost of the robotic system to the hospital. Current commercial systems are expensive, particularly in their initial capital costs. Furthermore, where funds to cover these costs can be made available, the maintenance (recurrent) inspection cost may also be a prohibitive factor. This is considered in the top tier rather than in a lower tier despite the fact that it can be, and is often cited as, a significant prohibitive factor to adopting a surgical robotic system. This is because, as a measure, it is highly variable and not necessarily dependent on the robotic system itself. Differences in business model and market trends could render a device cheaper. Health-spending per patient is different from country to country, and if effectiveness is shown, patient demand may force finance to be made available.

Usability refers to the interaction between the surgeon and the robotic system when operating. For example, the user interface of the system must be easy to use and easy to learn, particularly when the robotic system performs only a small part of the procedure or is seldom used. The interface should ideally be intuitive and comfortable to the surgeon's natural work flow. Overly complex and difficult to use interfaces add to lead times of any system and can significantly increase expense if the surgeon time is monopolised by training and frequent refresher courses. Furthermore, complex and misleading interfaces may increase instances of human error. An interface must be carefully and ergonomically designed to provide information needed by the surgeon during a surgical procedure with the option to access auxiliary information.

\subsection{Alternative methodologies}

Advances in the field of surgical robotics are the result of work conducted through one of several research paths, each with different aims, methods and requirements. The methodology outlined in this paper is a single type of research path, namely applied research, where the goal is to produce a useful product. There are, in general, four different research paths, namely surgeon-led research, pure research, applied research and engineering-led research. The definition of each is given in Table I with typical examples. It should be noted that the research paths are not discrete but interlinked, and there could be cases where one research path transforms into another as a project evolves.

Surgeon- and engineering-led research paths are the simplest of the different research paths. They have limited 
short-term goals and are relatively low-risk. The surgeon and engineer can follow these lines of research mostly in isolation from one another, and there is less need for the difficult transition from one academic discipline, with its own language, methods and culture, to the other. Their principal aims are, in general, purely exploratory or are the extensions of existing techniques or technology. Surgeonand engineering-led research paths make an important contribution to development of the other research paths. Engineering-led research is often the birthplace of ideas and concepts that form part of the engineers' collected experience when developing new devices. Surgeon-led research improves the way existing robotic systems are used, in some instances, by finding new and more profitable uses not intended by the original inventors. Conducting surgeonand engineering-led research contributes to the success of the pure and applied research paths.

Pure research is the most challenging of the research paths. The research goals tend to be nebulous, refined or abandoned as the research proceeds. This makes it difficult to define any clear structure or methodology to follow. It is fundamentally a non-linear process. It is also lengthy, requiring many years of research effort before any tangible results are gained, and high-risk, as there is a chance that no tangible results will ever occur. On the other hand, successful pure research has the most potential of all the research paths to fundamentally revolutionise surgical methods and improve patient outcome.

The pure research path generally involves both the surgeon and the engineer co-developing the problem. This requires a close surgeon-engineer relationship, with a high degree of cross-disciplinary interaction. Some stateof-the-art developments are following this research route, establishing a clinical need by co-developing novel treatment modalities for which robots are intrinsic. For example, the HeartLander robot proposes a novel design for a surgical endeffector. ${ }^{6}$ This system uses a miniature two-footed crawling robot that is able to attach and crawl across the epicardial surface of the heart and thus allow the surgeon to reach difficult areas to deliver myocardial injections or use other microtools through the robot's 2-mm working port without immobilising the heart.

Micro-robotics is another example of a pure research project with potentially significant development for robotics in surgery - though it has yet to be fully realised in any practical or commercial sense. However, potential areas for exploitation of this technology include microsurgery, cell handling and sensing and diagnosis, within the intraocular, cardiovascular and inner ear environments. A variety of designs have been proposed. Lu and $\mathrm{Kim}^{7}$ suggested a four-fingered microhand, actuated by inflating balloons at the joints, for the manipulation of small objects, such as cells. Other authors have advocated the use of swimming micro-robots to effectively extend the surgeon's reach inside the body without the need for invasive interventions. Such technology could be useful as a diagnosis facility by supplying specific information direct from the location under examination. A variety of swimming mechanisms have been proposed, including electromagnetic fins, ${ }^{8}$ oscillating elastic tails actuated by piezoelectrics, ${ }^{9}$ the use of external magnetic fields ${ }^{10}$ and biomimetic propulsion based on the flagellar motion of prokaryotic microorganisms. ${ }^{11}$ Dario and Menciassi ${ }^{12}$ are in the process of developing a capsule with legs which would enable it to crawl in the body for endoscopic analysis of the gastrointestinal tract. Such devices are in an early state of development, but there may be considerable potential to create new and possibly revolutionary operative methods if and when this technology matures.

Applied research is between the other research paths in terms of difficulty. In general, it has one overall goal the development of a surgical robot for a specific task. The surgeon-engineer relationship is more traditional with precise roles; the surgeon is effectively the client who decides the problem and provides feedback, the engineer is the problem-solver and product developer. The research is linear and a methodology, such as that described in this paper, could be followed to improve efficiency. Applied research is rarely revolutionary; however, in the medium term, it is the most likely of the research paths to produce new systems that have a clear effect on surgical methods.

\section{Evaluation of Commercial Surgical Robotic Systems}

Eleven commercial surgical robotic systems are evaluated against the methodology outlined in Section 2. The criterion for selection is that each robotic system has had published clinical trials listed in the PubMed database after 2005. A complete list of the robotic systems including a brief description of their function is included in the appendix. AESOP $^{\circledR}$ and Zeus ${ }^{\mathrm{TM}}$ are no longer promoted systems as of a recent merger between Computer Motion Inc. and Intuitive Surgical Inc., though both products continue to be supported. ROBODOC ${ }^{\circledR}$ was until recently withdrawn from sale after Integrated Surgical Systems temporarily ceased operations due to financial difficulties; however, it has reemerged with financial backing from Novatrix Biomedical Inc. The Naviot ${ }^{\circledR}$ system was withdrawn due to low sales and limited popularity of the device. Acrobot ${ }^{\circledR}$, SpineAssist ${ }^{\circledR}$ and Pathfinder ${ }^{\mathrm{TM}}$ are still under development and thus have few clinical trials and few units sold at present. Cyberknife ${ }^{\circledR}$ and the da Vinci ${ }^{\circledR}$ system are two of the more established robotic devices with a large number of clinical trials.

Clinical trials are chosen from the PubMed database using the robotic system name as a search term. The trials for each system and their respective quality score are shown in Table II. In the cases where the collected pool of evidence is small, all published clinical trials in English language are used for assessment. These are categorised as 'exhaustive' in Table II. For those with a large number of published trials, only larger studies (more than a hundred participants) in English language and post-2005 are used. These are categorised as '2005+, 100+' in Table II. The study size criterion for AESOP and Zeus is omitted to retain sufficient evidence for assessment of the device. This is categorised as '2005+'. The purpose of the chronological threshold is to ensure that the trials represent the most up-to-date version evidence. The trials for the da Vinci system are further refined to radical prostatectomy procedures to reduce the number and for ease of comparison. To date, radical prostatectomy is the most 
Table II. Surveyed clinical trials and classification.

\begin{tabular}{|c|c|c|c|c|c|}
\hline \multirow[b]{2}{*}{ System } & \multicolumn{4}{|c|}{ Clinical evidence (referenced papers) } & \multirow{2}{*}{$\begin{array}{l}\text { Evidence } \\
\text { selection }\end{array}$} \\
\hline & High & Moderate & Low & Very low & \\
\hline Acrobot & - & 20 & - & - & Exhaustive \\
\hline AESOP & 23 & - & 24,25 & - & $2005+$ \\
\hline Cyberknife & - & - & $26-28$ & - & $2005+, 100+$ \\
\hline da Vinci & $14,29,30$ & 15,16 & - & - & $2005+, 100+$ \\
\hline EndoAssist & - & - & $24,31,32$ & - & Exhaustive \\
\hline Naviot & - & - & 33 & 34,35 & Exhaustive \\
\hline NeuroMate & - & 22 & - & - & Exhaustive \\
\hline Pathfinder & & - & 36 & 37 & Exhaustive \\
\hline ROBODOC & 38 & 17 & 39 & - & $2005+, 100+$ \\
\hline SpineAssist & - & - & 40,41 & - & Exhaustive \\
\hline Zeus & - & $19,21,42$ & - & - & $2005+$ \\
\hline
\end{tabular}

Table III. GRADE evidence classification scheme ${ }^{13}$.

\begin{tabular}{ll} 
Grade of evidence & Criteria for assignment \\
\hline High & $\begin{array}{c}\text { Randomised controlled clinical trial or } \\
\text { systematic review } \\
\text { Upgraded observational study or downgraded } \\
\text { Moderate }\end{array}$ \\
Low & $\begin{array}{l}\text { Observational study } \\
\text { Very low }\end{array}$
\end{tabular}

common and successful procedure to be performed by this system.

Each clinical trial is assigned a quality grade: high, moderate, low or very low. The grades are based on definitions of the GRADE evidence classification scheme. ${ }^{13}$ The criteria for each grade of evidence are summarised in Table III. Clinical trials can be assigned higher or lower scores depending on their individual merit or demerit.

The study of ref. [14] is an observational study; it is upgraded twice from low to high, because it has a large sample size and also it directly compares robotic and nonrobotic alternatives. The large sample size suggests that evidence of association is likely to be strong. The comparison of robotic and non-robotic alternatives is non-randomised; however, patients are given a choice about treatment options. Bias towards a particular treatment is exposed by the patients' selection. References [15] and [16] are observational studies; these are upgraded once from low to moderate, because these have large sample sizes with directly measurable effects. The study of ref. [17] is an observational study; it is upgraded once from low to moderate, because it directly compares robotic and non-robotic alternatives. References [18] and [19] are observational studies; these are upgraded from low to moderate, as these directly compare robotic and conventional surgery in a non-randomised trial. References [20] and [21] include randomised clinical trials; these are downgraded from high to moderate, because these have a small sample size. Reference [22] is a randomised clinical trial; it is downgraded from high to moderate, because there is no postoperative follow-up of the patients. Reference [23] is a review paper; it is downgraded twice from high to low, as there is no comparison with alternative therapies, and few meaningful metrics are given to compare between surveyed trials.

\subsection{Clinical need}

The establishment of a clinical need should always be a precursor to the development of a surgical robotic system in applied research in order to ensure that the initial stages of the design specification are clinically driven, with a problem definition and thus clear objectives. Therefore, a deficiency in current surgical practice must first be identified; then the possibility that a robotic system may form part, or all, of the solution must be evaluated. Ideally, this definition phase will be based on a systematic approach led by a research partnership between surgeon and engineer, where the surgeon can provide a source of reference on the surgical procedures and critically evaluate proposed robotic solutions.

The major areas of clinical need among the evaluated commercial systems are shown in Table IV. They include bone resection, endoscope control, frameless stereotactic systems, minimally invasive surgery, screw placement and radiosurgery. Each area has a clearly defined deficiency in current surgical practice. Minimally invasive surgery, for example, is a technique able to minimise surgical trauma to the patient by performing surgical tasks through small incisions in the skin using trocars and microtools. However, such a technique is known to have a number of drawbacks for the surgeon. These include reduced depth perception from the use of an endoscopic camera, difficult hand-eye-target coordination, magnification of hand tremor through long instruments (e.g. the trocars), limited range of motion and degrees of freedom, reversed motion through the fulcrum point at the skin incision, limited tactile feedback and increased fatigue due to camera instability. ${ }^{43}$ Furthermore, there are a number of difficulties over the control of the endoscopic camera which, during surgery, is given to an operative assistant who must attempt to align the view of the camera according to the surgeon's instructions. The use of robotic systems for the control of an endoscope (camera), such as AESOP, EndoAssist ${ }^{\mathrm{TM}}$ or Naviot, can address this disadvantage by allowing the surgeon to control the camera directly through a convenient control interface such as a foot pedal or a finger joystick, or through more sophisticated means such as voice control or motion of the surgeon's head. ${ }^{44,45}$ More comprehensive, and thus more expensive, robotic systems, such as the da Vinci system or the Zeus system, go beyond simple camera manipulation by performing entirely minimally invasive interventions inside the body under direct surgeon control. Such robotic systems are based on a master-slave architecture that allows for processing and augmentation of the surgeon's inputs at the master-control for physical realisation at the slave-robot. The outcome of this is that the robotic device can mitigate many of the disadvantages of the minimally invasive technique by providing more precise and controlled motions at the robot tip, in addition to a more intuitive and user-friendly interface at the surgeon's console.

The accurate resection of bone or precise alignment tasks such as pedicle screw placement in the spine and the locking of an intramedullary nail in femoral shaft fractures require a relatively high degree of three-dimensional accuracy. This 
Table IV. Description of clinical need.

\begin{tabular}{|c|c|c|}
\hline Clinical need & Description & Robotic systems \\
\hline Bone resection & $\begin{array}{l}\text { The accurate cutting of bone in, for example, knee joint surgery (Acrobot) and for } \\
\text { placement of prostheses or implants. }\end{array}$ & $\begin{array}{l}\text { - Acrobot } \\
\text { - ROBODOC }\end{array}$ \\
\hline Endoscope control & $\begin{array}{l}\text { Robot holds and moves an endoscopic camera under surgeon control during } \\
\text { minimally invasive surgery. Normally held by an operative assistant who must } \\
\text { attempt to predict the optimum view based on the surgeon's instructions, and hold } \\
\text { the camera steady with minimum tremor. }\end{array}$ & $\begin{array}{l}\text { - AESOP } \\
\text { - EndoAssist } \\
\text { - Naviot }\end{array}$ \\
\hline Frameless stereotactic surgery & $\begin{array}{l}\text { A stereotactic frame is used to align a tool-guide with a calculated desired trajectory. } \\
\text { The frame is mounted (post pre-operative imaging) on to a base ring, which is } \\
\text { attached to the patient's head prior to pre-operative imaging. Attaching the base } \\
\text { ring to the patient's head requires an additional procedure. }\end{array}$ & $\begin{array}{l}\text { - NeuroMate } \\
\text { - Pathfinder }\end{array}$ \\
\hline Minimally invasive surgery & $\begin{array}{l}\text { Performing surgery through a set of small incisions in the body using trocars with } \\
\text { microtools at the distal end, and an endoscopic camera. }\end{array}$ & $\begin{array}{l}\text { - da Vinci } \\
\text { - Zeus }\end{array}$ \\
\hline Screw placement & $\begin{array}{l}\text { Accurate placement of screw/nails in surgery. For example, the placement of pedicle } \\
\text { screws in lumbar spinal fusion or locking of intramedullary nail in femoral shaft } \\
\text { fracture. }\end{array}$ & - SpineAssist \\
\hline Radiosurgery & $\begin{array}{l}\text { Use of targeted radiation doses to ablate malignant tumours and benign lesions. High } \\
\text { levels of accuracy required to make radiation dose conform to tumour shape and } \\
\text { minimise damage to surrounding tissue. Often performed with a stereotactic frame. }\end{array}$ & - Cyberknife \\
\hline
\end{tabular}

is a challenging task for a surgeon to perform manually as it requires a complex transformation from imaging data to physical space. A robotic system can register its workspace to an image set and is thus able to perform a part or the entire procedure either actively - for instance in the case of ROBODOC which performs bone resection autonomously or passively by providing guidance for the surgeon to perform the procedure accurately - for instance SpineAssist, a robotic device that is attached to the spine to provide a physical guide for the surgeon to orientate the pedicle screws. Acrobot, in contrast, is a hybrid of active and passive systems which uses active force control and dynamic constraints to restrain the surgeon's freedom. In this case, the surgeon retains direct control of the end-effector (cutting tool), but is constrained by the robot to cutting within a permitted region programmed pre-operatively using imaging data.

A stereotactic frame is a mechanical device that is commonly used in neurosurgery for precise targeting of structures within the cranium. However, the disadvantages associated with these frames include the following: (1) a secondary procedure is required to fit the base ring of the frame, (2) the frame is bulky and uncomfortable for the patient and (3) guide positioning can be time-consuming and is a potential source of errors. ${ }^{46}$ Robotic systems, such as NeuroMate ${ }^{\circledR}$ and Pathfinder, have thus been proposed that can register to pre-operative images and can provide an accurate frameless option for guide positioning. Similarly, robotic systems such as Cyberknife have been used to overcome the problems associated with stereotactic frames in radiosurgery procedures - the treatment of brain disorders using ionising radiation - with additional benefits such as extracranial radiosurgery and motion tracking. ${ }^{27}$

\subsection{Clinical effectiveness}

A surgical robotic system must demonstrate at least equivalent levels of effectiveness to a conventional nonrobotic approach to gain clinical acceptance. Furthermore, the decision to adopt a robotic system for surgery will ultimately be based on a cost-to-benefit ratio and so a system that can demonstrate effectiveness greater than a non-robotic intervention will have a high potential for success.

Effectiveness can be assessed through direct comparison in clinical trials. The ideal clinical trial has a large sample group, is randomised and double-blind and is multi-centred to take account of differing surgeon skills and methods and hospital protocols. However, in practice it can be difficult to build a sufficiently large body of evidence of this kind of quality to draw conclusions regarding a system's effectiveness. Firstly, this process is costly, time-consuming and takes a number of years to complete. Most surgical robotic enterprises are small and lack the infrastructure and resources of major organisations. Secondly, it is difficult to directly compare non-robotic surgery to robotic surgery. Surgical methods and experience differ between surgeons and institutions, with some having better, and some worse, than average surgical outcomes. Thus, when comparing the results of a robotic surgery with a non-robotic equivalent surgery, the difference in outcome could be overstated or understated. Clinical trials are a vital resource for assessing effectiveness; however, more high-quality trials are necessary for robust assessments.

The evidence for effectiveness of each of the surgical robotic systems is summarised in Table V. The information is taken from a review of clinical trials referenced in Table II. Three metrics are considered and compared to a specific non-robotic procedure: functional or symptomatic outcome, operative outcome and failure rate. Functional or symptomatic outcome is the resulting benefit to the patient's quality of life after the operation, for instance, the time taken for the patient to regain some previously impaired function, e.g. walking. Operative outcome refers to measurable improvements in the performance of the surgery. Examples include accuracy, blood loss and occurrences of minor complications. Functional or symptomatic outcome is the more important of these two outcomes as it is directly linked to the patient's recovery. Operative outcome is only of value if it conveys some post-operative effect. Both 
Table V. Review of clinical trials for clinical effectiveness.

\begin{tabular}{|c|c|c|c|c|c|}
\hline Robotic system & Comparative surgery & $\begin{array}{l}\text { Changes in functional/symptomatic } \\
\text { outcome }\end{array}$ & Changes in operative outcome & $\begin{array}{l}\text { Fail } \\
\text { rate }(\%)\end{array}$ & $\begin{array}{l}\text { Evidence } \\
\text { quality }\end{array}$ \\
\hline Acrobot & Arthroplasty & $\begin{array}{l}\text { Median AKS scores at } 6 \text { weeks: } 3 \\
\text { (approx.) }\end{array}$ & $\begin{array}{l}\text { Proportion of resections within } \\
2^{\circ} \text { of planned position: } \mathbf{2 . 5}\end{array}$ & NR & Moderate \\
\hline \multirow[t]{2}{*}{ AESOP } & $\begin{array}{l}\text { Laparoscopic } \\
\text { cholecystectomy }\end{array}$ & NR & NR & NR & High \\
\hline & Laryngoscopy & & & & Low \\
\hline \multirow[t]{2}{*}{ Cyberknife } & $\begin{array}{l}\text { GammaKnife }{ }^{\circledR} \\
\text { radiosurgical } \\
\text { system }\end{array}$ & $\begin{array}{l}\text { Progression-free survival: } \mathbf{0 . 9 8} \\
\quad \text { Radiation-related morbidity: } \mathbf{0 . 1}\end{array}$ & $\begin{array}{l}\text { Can treat extra-cranial tumours } \\
\text { Can treat moving parts, e.g. } \\
\text { lungs Proportion of patients } \\
\text { that can be treated: } \mathbf{1 . 4 6}\end{array}$ & NR & Low \\
\hline & LINAC & $\begin{array}{l}\text { Progression-free survival: 0.98 } \\
\quad \text { Radiation-related morbidity: } \mathbf{0 . 1 5}\end{array}$ & & & Low \\
\hline \multirow[t]{2}{*}{ da Vinci } & $\begin{array}{l}\text { Laparoscopic radical } \\
\text { prostatectomy }\end{array}$ & $\begin{array}{l}\text { Proportion of patients continent } \\
\text { after } 3,6,12 \text { months: } \mathbf{0 . 9 6}-\mathbf{1 . 4 3} \\
\mathbf{1 . 0 1 - 1 . 1 2 , 1 . 0 3 - 1 . 5 3 ~ S e x u a l ~} \\
\text { potency: } \mathbf{0 . 5 7 - 1 . 2 3}\end{array}$ & $\begin{array}{l}\text { Blood loss: 0.37-0.48 } \\
\text { Complication: } \mathbf{0 . 4 2 - 0 . 7 8} \\
\text { PSM: 0.64-1 }\end{array}$ & NR & High \\
\hline & $\begin{array}{l}\text { Open radical } \\
\text { prostatectomy }\end{array}$ & $\begin{array}{l}\text { Proportion of patients continent } \\
\text { after } 3,6,12 \text { months: } \mathbf{1 . 2 8}-\mathbf{1 . 3 5} \text {, } \\
\mathbf{1 . 1 1 - 2 . 1 2 , 1 . 0 8 - 1 . 5 2 ~ S e x u a l ~} \\
\text { potency: 0.66-1.12 } \\
\text { Post-operative pain scores: } \mathbf{0 . 4 5}\end{array}$ & $\begin{array}{l}\text { Blood loss: 0.1-0.27 } \\
\text { Complications: } \mathbf{0 . 3 3 - 0 . 6 4} \\
\text { PSM: 0.53-1 }\end{array}$ & & \\
\hline \multirow[t]{2}{*}{ EndoAssist } & $\begin{array}{l}\text { Laparoscopic } \\
\text { cholecystectomy }\end{array}$ & NR & NR & NR & Low \\
\hline & $\begin{array}{l}\text { Laparoscopic radical } \\
\text { prostatectomy }\end{array}$ & & & $0 \%$ & \\
\hline \multirow[t]{2}{*}{ Naviot } & $\begin{array}{l}\text { Laparoscopic } \\
\text { cholecystectomy }\end{array}$ & NR & NR & NR & Low \\
\hline & Thoracic surgery & & & & Very low \\
\hline NeuroMate & $\begin{array}{l}\text { Stereotactic } \\
\text { neurosurgery }\end{array}$ & Score on UPDRS: 1 (approx.) & Accuracy: 1 or less (approx.) & NR & Low \\
\hline Pathfinder & $\begin{array}{l}\text { Stereotactic } \\
\text { neurosurgery }\end{array}$ & NR & Accuracy: 0.5 (approx.) & NR & Low \\
\hline \multirow[t]{3}{*}{ ROBODOC } & Arthroplasty & $\begin{array}{l}\text { Proportion of patients gaining } \\
\text { walking ability in }<13 \text { days: } \mathbf{1 . 3 4}\end{array}$ & $\begin{array}{l}\text { Blood loss: } 0.75 \text { MDA after } 2 \\
\text { yrs: 1.01 Fracture: } 0 / \mathbf{6}^{*} \\
\text { Average position error: } \mathbf{0 . 6 5}\end{array}$ & NR & High \\
\hline & & NR & $\begin{array}{l}\text { Accuracy: 0.53 Proportion of } \\
\text { good fit with implant: } \mathbf{1 . 7 6}\end{array}$ & & Moderate \\
\hline & & & NR & 9.3 & Low \\
\hline SpineAssist & $\begin{array}{l}\text { Pedicle screw } \\
\text { placement }\end{array}$ & NR & $\begin{array}{l}\text { Proportion of screw placement } \\
\text { within pedicle: } \mathbf{1 . 1 5 - 1 . 2 3}\end{array}$ & $6.5-6.7$ & Low \\
\hline \multirow[t]{2}{*}{ Zeus } & $\begin{array}{l}\text { Laparoscopic } \\
\text { cholecystectomy }\end{array}$ & NR & Number of cleanings: $\mathbf{0 . 2 4}$ & $0 \%$ & Moderate \\
\hline & $\begin{array}{l}\text { Laparoscopic } \\
\text { adrenalectomy }\end{array}$ & & NR & & \\
\hline
\end{tabular}

NR: none reported; (approx.) indicates that the ratio is derived from qualitative statements or subjective or imprecise data; AKS: American Knee Society; UPDRS: Unified Parkinson's disease rating scale; MDA: Merle d'Aubigne score; PSM: positive surgical margin.

Numbers in bold are ratios of robot performance and comparative surgery performance.

${ }^{*}$ Performance given as a fraction because ratio is zero (as there is a zero in robot performance).

outcomes are assessed relative to a comparative surgical procedure using ratios (in bold in Table V) equal to robot performance divided by comparative surgery performance. For example, a high ratio for accuracy indicates that better accuracy is obtained for the robot system compared to the non-robotic procedure. The third metric is failure rate, which considers instances of breakdown of the robotic system or its supporting components. In many cases, system failure leads to completion of the surgical procedure using conventional techniques. Thus, high failure rate diminishes the justification for the robotic system. The strength/validity of each result in Table $\mathrm{V}$ is assessed by the respective evidence quality in the last column using the GRADE system described previously (Table III).

There is significant evidence of improved operative outcomes as a result of robotic assistance in surgery. Robotic systems developed for bone resection, stereotactic surgery and screw placement (Acrobot, ROBODOC, Pathfinder, NeuroMate and SpineAssist) all show either improved accuracy (ratios below 1) or a higher proportion of correct 
placements (ratios above 1) when compared to conventional surgery. The da Vinci system showed reduced blood loss during operation (ratio below 1) and higher precision when resecting tumourous material (positive surgical margins with ratio below 1) when compared to both open and laparoscopic procedures. The ROBODOC system also had reduced blood loss. The Cyberknife system has extended the scope of radiosurgery by increasing the proportion of patients, and the types of tumours which the therapy can safely treat. The endoscopic systems (AESOP, EndoAssist and Naviot) reported no change in operative outcome, because the principle objective for endoscopic systems is for cost reduction and increased surgeon control, i.e. reducing the size of the operative staff, and hence no change in operative outcome would be expected.

There is less evidence to show improved functional or symptomatic outcome - in contrast to the evidence for improved operative outcome. Only the Acrobot, Cyberknife, da Vinci and ROBODOC systems have evidence to indicate improvement in this metric. Acrobot has shown improvement in the median American Knee Society scores post-operatively in a randomised controlled clinical trial. However, the sample size of the study was small - the Acrobot system was used only on 13 individuals. Despite the result being statistically significant in the study, larger studies are necessary for validation. ROBODOC showed functional or symptomatic benefit in a larger randomised trial - it was used on 78 patients. However, the link between use of the system and functional benefit is unclear. The larger proportion of patients gaining the ability to walk within 13 days in the ROBODOC group only just reaches statistical significance. The study found no overall statistically significant difference between the two groups in the overall time required to gain the ability to walk. The Cyberknife system has some evidence to show lower radiation-induced morbidity. However, the evidence quality grade is low.

The da Vinci system has shown improved return-tocontinence rates and sexual potency when compared to conventional laparoscopic and open radical prostatectomy procedures. For the latter procedure, the da Vinci system has also shown decreased post-operative pain. Functional or symptomatic outcomes are assessed through periodic patient follow-up, which is conducted through questionnaires and interviews. Consequently, there is the risk of bias skewing the results if the trials are not blinded. The bulk of the evidence for the da Vinci system is based on unblinded large single-centre observational studies. Evaluation of the da Vinci system has used systematic reviews of these clinical trials. This improves the quality of the evidence significantly by comparing results from different institutions, but there is still a high risk of bias in follow-up investigations. This risk may increase as the public profile of the da Vinci system grows through exposure in media outlets and advertising.

There is insufficient published information in the surveyed literature to assess the failure rate, and therefore the reliability of the robotic systems. In the clinical studies, technical failures are rarely reported. One interpretation of this omission is that failures are sufficiently uncommon to be negligible; however, a more quantitative analysis is necessary.
Robotic assistance in surgery could improve operative outcomes such as reduced blood loss, greater precision or increased accuracy. However, improved operative outcomes do not always translate into functional or symptomatic benefits for the patient. The surveyed clinical evidence shows limited improvement in functional or symptomatic outcomes in contrast to the significant improvements in operative outcomes. This can be partly attributed to limitations in the clinical evidence base, which prevents inference of any conclusive long-term and post-operative trends.

\subsection{Safety}

In addition to effectiveness, safety compliance is a major design requirement in surgical robotic systems. Unlike traditional robotics, where the assumption has been that an operator will be isolated from the robot's workspace while in operation, surgical robotic systems work either invasively or in close proximity to a patient or surgical team. Thus far, designers have drawn on a number of common approaches to ensure safety in their design. For example, restricted motion and force, redundant sensors and hardwired manual emergency methods have all been employed in different arrangements for both commercial and research systems. These approaches can be restrictive to a robot's function. For instance, restricting motion and force limits the range of possible tasks the robotic system can perform.

A rational structured methodology is a key requirement to proving safety. As yet, no specific standard exists for medical robots, but a number of standards do exist for medical devices (IEC601, ISO 14971), industrial robotics (ISO 10219) and safety-related systems (IEC 1508) from which the principal features can be extracted. A number of authors have published methodologies that ensure safety based on their experience in the design and development of a surgical robotic system. These methodologies include the hazard identification and safety insurance control (HISIC) method, ${ }^{47}$ an evolutionary prototype method ${ }^{48}$ and a unified modeling language (UML)-based approach. ${ }^{49}$ In broad terms, safe design can be seen as a four-step, iterative and evolutionary process, consisting of a system definition phase, a risk identification and quantification phase, a risk control phase and a risk evaluation phase. These phases are clarified below.

To produce a system definition the system must be described in terms of its function, its relationship with the operator and patient and its relationship with other third parties such as maintenance engineers or setup technicians required for it to operate correctly. This effectively requires (1) a thorough task analysis, considered holistically, i.e. set up before, during, and after operation, as well as during storage; (2) a task allocation exercise to fully appreciate the robot's function and how it interacts with its environment and patient/operators; (3) a functionality analysis to define the system and its subsystems; and where appropriate, (4) the identification of safety critical limits that form the boundary between safe and unsafe states.

The aim of the risk identification phase is to identify all hazards, their consequences and their risks and to categorise these risks by order of priority. Seven major areas of risk in surgical robotics have been identified as image processing and planning, registration, robot motion, 
Table VI. Examples of safe design in surgical robotic systems.

\begin{tabular}{|c|c|}
\hline $\begin{array}{l}\text { Design } \\
\text { method }\end{array}$ & Examples \\
\hline $\begin{array}{l}\text { Redesign to } \\
\text { eliminate } \\
\text { hazards }\end{array}$ & $\begin{array}{l}\text { - Non-invasive } \\
\text { - Mechanically locked centre of rotation about } \\
\text { incision point } \\
\text { - Mechanically locked when in position } \\
\text { - Excessive motion detection } \\
\text { - Dual sensors to disable robot if discrepancy } \\
\text { detected } \\
\text { - Direct surgeon control with robot augmenta- } \\
\text { tion (master-slave) }\end{array}$ \\
\hline $\begin{array}{l}\text { Protection } \\
\text { and } \\
\text { safeguards }\end{array}$ & $\begin{array}{l}\text { - Velocity limiters } \\
\text { - Limited possible motion/work envelope } \\
\text { - Slip clutches to limit applied torque/force } \\
\text { - Software defined no-go zones } \\
\text { - Low-powered }\end{array}$ \\
\hline $\begin{array}{l}\text { Warning user } \\
\text { of danger }\end{array}$ & $\begin{array}{l}\text { - Visible difference between sterilisation and } \\
\text { draping parts of robot } \\
\text { - No go zones for operator and patient } \\
\text { - Clear HMI (human-machine interface) }\end{array}$ \\
\hline
\end{tabular}

reliability of control, vigilance (i.e. the ability of the surgeon to take action), hygiene/sterilisation and clinical work flow. ${ }^{50}$ Formal methods for the quantification of risks include faulttree analysis, event tree analysis and failure mode effects analysis.

The risk control phase is to put in place measures to reduce the risks identified in the risk identification phase to a state where they are eliminated or negligible or 'as low as reasonably possible' (the ALARP principle). Risk can be mitigated by reducing either the probability or the severity, or by a combination of both. There are three design methods that can be used in order to derive appropriate risk control measures. These are redesigning to eliminate hazards, control through protection and safeguards and control through user warnings. ${ }^{51}$ Each method encompasses a number of specific techniques for safe design. Redesigning to eliminate hazards includes designing redundancy in the system or designing for intrinsic safety; protection and safeguards can be achieved by using limiters and providing for 'graceful degradation' or fault tolerance; and finally, user warnings involves mitigating risk through communication with the user and allowing their actions and judgement to be used to reduce the risk. Table VI gives examples of ways in which the risk control methods outlined have been realised in the reviewed surgical robotic systems.

The risk evaluation phase is to evaluate the control parameters put in place in the risk control phase and assess their suitability in the overall design of the system. Where a parameter is found to be unsuitable, the process must be repeated with the parameter replaced or modified. This repetition makes the process both iterative and evolutionary.

The use of robotic systems in a surgical environment necessitates that sterilisation be considered in the design. This can be a challenging condition as traditional sterilisation techniques are aggressive and not always compatible with conventional robotic components. For instance, autoclaving is a common and popular method of sterilisation due to its rapidity and availability. However, not all electronic components that are used in the autoclaving process are able to withstand temperatures over $100^{\circ} \mathrm{C}$. The most common approach to maintaining a sterile environment is to partly cover the surgical robotic device with surgical drapes and use a sterilisable end-effector. This method is not entirely satisfactory because of the need for attachment mechanisms needed to secure the end-effector and to transmit sensing and/or drive signals between the draped part and the sterilisable (or disposable) part.

\subsection{Compatibility}

Compatibility is considered in two respects: compatibility with existing medical equipment and compatibility with the robotic system's working environment. There are no reports of compatibility issues with existing medical equipment within the surveyed literature. This could be because no problems were observed during the clinical trials. However, compatibility was not a focus of any of the surveyed clinical trials, but a peripheral issue compared to system efficacy. Many of the clinical trials are small, one-off events run by a host institution. Any problems with equipment compatibility would likely become more apparent with wider use, e.g. highfrequency use would cause compatibility issues to become more of an annoyance to the user, and use in multiple centres would expose the system to a wider variety of different equipment options.

The size of the robotic system is the most prominent issue of environmental compatibility. Operating rooms are often small and cluttered spaces. The large footprint of most of the robotic systems can cause an obstruction that interrupts the surgical team's work flow. One notable exception is the SpineAssist system, which has been designed to have a minimised footprint - around the size of a drinks can. This unfortunately has been at a cost to its usability, where its small size has, on occasions, prevented it from reaching a target, requiring intra-operative repositioning by the surgeon.

\subsection{Cost}

A surgical robotic system could be a considerable capital expense. A high initial outlay will not necessarily prevent a device from being adopted as long as it fulfils the criteria of clinical need and safety and can demonstrate clinical effectiveness. However, high cost can limit the implementation of a robotic system to larger hospitals, research institutions and expensive private clinics. This has certainly been the case with the da Vinci system. Two studies analysing the cost of the da Vinci system have been published, one comparing retropubic (open) radical prostatectomy (ORP) to robotic radical prostatectomy (RRP), ${ }^{52}$ and a second comparing the same procedures with laparoscopic radical prostatectomy (LRP). ${ }^{53}$ Costs were approximated for a private academic medical centre and a public county hospital. In both cases, the initial capital cost of the da Vinci system was assumed to be amortised over 7 years. The results of both studies show RRP to be the most expensive treatment option under normal circumstances: costing \$1726 and \$1,239 more per procedure than ORP and LRP respectively in the county hospital, and between $\$ 195$ and $\$ 783$ more than ORP in the private medical centre, using 
Table VII. Robotic system usability.

\begin{tabular}{|c|c|c|c|c|c|}
\hline Robotic system & Comparative surgery & Operative time & Learning curve & Evidence quality & Surgeons' comments \\
\hline Acrobot & Arthroplasty & $1.18(n S F)$ & NR & Moderate & \\
\hline \multirow[t]{2}{*}{ AESOP } & Laparoscopic cholecystectomy & 1.28 & NR & High & \\
\hline & Laryngoscopy & 1 (approx.) & $4^{a}$ (approx.) & Low & $\begin{array}{l}\text { Voice commands not always } \\
\text { effective due to background } \\
\text { noise }\end{array}$ \\
\hline Cyberknife & $\begin{array}{l}\text { Gammaknife } \\
\text { LINAC }\end{array}$ & NR & NR & Low & \\
\hline \multirow[t]{2}{*}{ da Vinci } & $\begin{array}{l}\text { Laparoscopic Radical } \\
\text { prostatectomy }\end{array}$ & $0.6-0.83$ & $20^{a}$ & High & $\begin{array}{l}\text { Operating from workstation } \\
\text { increases surgeon comfort }\end{array}$ \\
\hline & & & $150^{b}$ & Moderate & Lack of force feedback \\
\hline \multirow[t]{2}{*}{ EndoAssist } & Laparoscopic cholecystectomy & $-10 \min$ & $3^{a}$ & Low & $\begin{array}{l}\text { One of the six surgeons found } \\
\text { the device unsuitable and } \\
\text { was excluded from study }\end{array}$ \\
\hline & $\begin{array}{l}\text { Laparoscopic radical } \\
\text { prostatectomy with AESOP* }\end{array}$ & $-31.3 \mathrm{~m}(\mathrm{nSF})$ & NR & Low & $\begin{array}{l}\text { No speed adjustment. Large } \\
\text { camera panning was slow }\end{array}$ \\
\hline \multirow[t]{2}{*}{ Naviot } & Laparoscopic cholecystectomy & 1.19 & NR & Low & \\
\hline & Thoracic surgery & +10 min (approx.) & NR & Very Low & \\
\hline NeuroMate & Stereotactic neurosurgery & NR & NR & Low & $\begin{array}{l}\text { Pre-operation required for } \\
\text { registration }\end{array}$ \\
\hline Pathfinder & Stereotactic neurosurgery & 0.77 & NR & Very low & \\
\hline ROBODOC & Arthroplasty & 1.2 & NR & High & $\begin{array}{l}\text { Pre-operation required for } \\
\text { registration }\end{array}$ \\
\hline SpineAssist & Pedicle screw placement & +15 min (approx.) & $15^{b}$ (approx.) & Low & \\
\hline \multirow[t]{2}{*}{ Zeus } & Laparoscopic cholecystectomy & 1.571 .32 & NR & Moderate & \\
\hline & Laparoscopic adrenalectomy & 1.43 & $20^{b} \mathrm{~h}$ & Moderate & \\
\hline
\end{tabular}

NR: none reported; (approx.) indicates that the ratio is derived from qualitative statements or subjective or imprecise data.

Numbers in bold are ratios of robot-performance and comparative surgery performance.

*AESOP was controlled by remote control rather than by voice activation (as is typical).

Operative time:

$+/-$ : Additional (+) or reduced (-) minutes to overall operating time.

nSF: No statistical significance.

Learning curve:

${ }^{a}$ Number of attempts before parity with a conventional procedure.

${ }^{b}$ Number of attempts before plateau of the learning curve.

post-operative 'lengths of stay' based on other specialist centres ( 2.5 days) and the U.S. national mean (3.5 days) respectively. The principal discrepancy between the two sets of figures is the daily cost of hospital stay, which is higher in the private academic medical centre ( $\$ 840$ per day vs. $\$ 474$ ). Therefore, in order for ORP to be cost-equivalent with RRP, hospital stay would have to be approximately $\$ 950$ per day. Changes in hospital-stay costs would not reduce the cost advantage of LRP compared to RRP as they both have the same length of stay.

As shown in these studies, despite the popularity of the da Vinci system, particularly in the United States, the purely financial case for adoption in surgery is weak, even in specialist surgical centres. However, as for any robotic system, the financial case must take into account the clinical effectiveness.

\subsection{Usability}

The ease of use of a robotic system, or its usability, can be very subjective, dependent on the user's personal view, experience and propensity towards new technology. Usability can also be a very broad term, encompassing all aspects of the system ergonomics, interface, performance and intuitiveness. Here, we define usability according to two quantitative metrics: time of operation and learning curve. Time of operation is defined as the time from initial setup to completion of the operation. The learning curve is defined in two ways: (1) the number of attempts before the operative time reaches parity with the non-robotic procedure, and (2) when the surgeon's operative time does not change with more attempts (the learning curve plateaus). Usability information for the surveyed clinical trials is summarised in Table VII. An additional column is included for general comments made by surgeons. Though this is subjective, it is nonetheless of interest as it provides insights that may not be directly evident in the chosen metrics.

The clinical trials for the da Vinci, EndoAssist and SpineAssist systems have information relating to learning curve. However, this information is obtained from speculative assessments based on experience of the operators. The learning curves are relatively short for the EndoAssist and SpineAssist robotic systems. The da Vinci system has widely varying judgements on the length of the learning curve and no conclusion can be reached. The learning curves are not overly important in the majority of the robotic systems as they do not substantially change the work flow of the operation. However, the minimally invasive systems (da Vinci and Zeus) substantially change the way the procedure is performed 
- the entire process is performed with the surgeon at a console. For minimally invasive systems, however, the question is not the length of the absolute learning curve, but the length of the learning curve relative to conventional laparoscopic surgery.

All the surgical robotic systems include information on operative time. In general, most robotic systems reduce the overall operative time (ratios less than 1) despite additional setup requirements. The exceptions are Naviot, ROBODOC, SpineAssist and Zeus. Acrobot also increased operative time on average; however, this was not statistically significant when compared to conventional arthroplasty. The EndoAssist system had lower operative times; however, one of the six assessed surgeons had to abandon the study due to difficulties in using the device. This problem was not reported in clinical trials for other systems, though it may still have occurred. The results for operative time are indicative rather than conclusive. A fair assessment would require a range of surgeons with different skill levels. The surveyed clinical trials tend to be single-centred with only a small number of participating surgeons. Furthermore, operative times change with familiarity. Despite the limitations of the evidence, surgical robotic systems overall have a positive impact on operative time.

\section{Conclusions}

The rate of growth of surgical robotics in the academic field has continued to increase over recent years. As a practical commercial reality, this impact is disproportionately low. It is important for the transfer of research into commercial reality that the surgical robotic community learn to build on its strengths and mitigate its weaknesses. With the proliferation of research in this field expanding the mass of literature, there is an increasing danger that past lessons will be overlooked. Research in surgical robotics can be divided into four main research paths, namely surgeon-led research, engineering-led research, pure research and applied research. A methodology for applied research has been presented, which can be used to critically evaluate a perceived robotic opportunity in surgery.

The applied research methodology consists of six criteria which are used to evaluate a surgical robotic system; these are clinical need, clinical effectiveness, safety, cost, compatibility and usability. The respective importance of each criterion is determined by its position in a three-tiered hierarchy, consisting of the most important in the bottom tier, the medium important in the intermediate tier and the least important in the top tier. The division of criteria into the individual tiers is as follows: the base tier consists of establishing the clinical need, the intermediate tier consists of safety and clinical effectiveness and the top tier consists of compatibility, cost and usability. Furthermore, the value added by performing well against a particular criterion is dependent on satisfying the criteria in the tiers below it. For example, a strong performance against one of the criteria in the top tier will only add value to a robotic system if the criteria of the bottom and intermediate tier can be shown to have been satisfied.

All the robotic surgical systems described achieve the bottom tier of the hierarchy, establishing a clinical need by identifying a deficiency in current surgical practice, and by outlining a method by which a robotic system can form a part or all of a solution. One of the reasons for the considerable success of the da Vinci robotic system relative to the other robotic systems is that it has been designed to mitigate the disadvantages of a surgical technique, and thus has multiple applications, wherever this technique can be applied.

The evaluated robotic systems also satisfy the criteria of the intermediate tier, although to a more variable degree compared to the bottom tier. For instance, while surgical robotic systems are able to demonstrate competence in clinical effectiveness and are safe to use, they cannot clearly establish improved symptomatic outcome, even when the surgical improvement is clear and measurable. The pool of clinical evidence is relatively small, and is of insufficient size and quality to provide conclusive results. Evaluation against the top tier gives an even more variable outcome, with many robotic systems scoring well in one criterion but not in others. For example, the da Vinci system offers superior usability when compared to the difficulties of minimally invasive surgery, but is expensive to buy and run (service costs) as well as difficult to fit in a standard operating room. The mixed results of the top tier have not precluded any of the robotic systems from having some success, but from the frequent surgeon comments referring to these criteria as disadvantages, it is undoubtedly a restraining factor.

The lack of fulfilment of the criteria of the top tier, namely cost, usability and compatibility, acts against these commercial systems - with most robotic systems scoring well only in one of the categories. However, the most significant contributory factor is perhaps that the robotic systems reviewed cannot show significant improvement relative to their cost. It is argued that, in the main, the absence of solid and tangible evidence of improved symptomatic outcomes is responsible for restraining the wide take-up of surgical robotics.

\section{References}

1. Y. S. Kwoh, J. Hou, E. A. Jonckheere and S. Hayati, "A robot with improved absolute positioning accuracy for CT guided stereotactic brain surgery," IEEE Trans. Biomed. Eng. 35(2), 153-160 (1988).

2. R. H. Taylor and D. Stoianovici, "Medical robotics in computer-integrated surgery," IEEE Trans. Robotics Automat. 19(5), 765-781 (2003).

3. P. Dario, B. Hannaford and A. Menciassi, "Smart surgical tools and augmenting devices," IEEE Trans. Robotics Automat. 19(5), 782-792 (2003).

4. B. Davies, "A review of robotics in surgery," Proc. Inst. Mech. Eng. Part H: J. Eng. Med. 214(H1), 129-140 (2000).

5. P. P. Pott, H. P. Scharf and M. L. Schwarz, "Today's state of the art in surgical robotics," Comput. Aided Surg. 10(2), 101-132 (2005).

6. N. A. Patronik, M. A. Zenati and C. N. Riviere, "Preliminary evaluation of a mobile robotic device for navigation and intervention on the beating heart," Comput. Aided Surg. 10(4), 225-232 (2005)

7. Y. W. Lu and C. J. Kim, "Microhand for biological applications," Appl. Phys. Lett. 89(16), (2006).

8. S. Guo, J. Sawamoto and Q. Pan, "A novel type of microrobot for biomedical application," International Conference on Intelligent Robots and Systems, Alberta, Canada (2005).

9. G. Kosa, M. Shoham and M. Zaaroor, "Propulsion of a swimming micro medical robot," Proceedings of the 2005 
IEEE International Conference on Robotics and Automation, Alberta, Canada (2005).

10. K. B. Yesin, K. Vollmers and B. J. Nelson, "Modeling and control of untethered biomicrorobots in a fluidic environment using electromagnetic fields," Int. J. Robotics Res. 25(5/6), 527-536 (2006).

11. M. Sitti and B. Behkam, "Modeling and testing of a biomimetic flagellar propulsion method for microscale biomedical swimming robots," Proceedings of the 2005 IEEE/ASME International Conference on Advanced Intelligent Mechatronics, Monterey, CA (2005).

12. P. Dario and A. Menciassi, "Frontiers of robotics in surgery: Endoluminal, endoscopic microcapsules and beyond," IMechE Seminar on Robotic Surgery - Recent Success and Future Direction, London, UK (2008).

13. D. Atkins, D. Best, P. A. Briss, M. Eccles, Y. Falck-Ytter, S. Flottorp, G. H. Guyatt, R. T. Harbour, M. C. Haugh, D. Henry, S. Hill, R. Jaeschke, G. Leng, A. Liberati, N. Magrini, J. Mason, P. Middleton, J. Mrukowicz, D. O'Connell, A. D. Oxman, B. Phillips, H. J. Schunemann, T. T. Edejer, H. Varonen, G. E. Vist, J. W. Williams, Jr. and S. Zaza, "Grading quality of evidence and strength of recommendations," BMJ Clin. Res. 328(7454), 1490 (2004)

14. M. Menon, A. Shrivastava and A. Tewari, "Laparoscopic radical prostatectomy: Conventional and robotic," Urology 66(5 Suppl.), 101-104 (2005).

15. M. Menon, A. Shrivastava, S. Kaul, K. K. Badani, M. Fumo, M. Bhandari and J. O. Peabody, "Vattikuti Institute prostatectomy: Contemporary technique and analysis of results," Eur. Urol. 51(3), 648-657; discussion 657-648 (2007).

16. D. G. Murphy, M. Kerger, H. Crowe, J. S. Peters and A. J. Costello, "Operative details and oncological and functional outcome of robotic-assisted laparoscopic radical prostatectomy: 400 cases with a minimum of 12 months followup," Eur. Urol. 55(6), 1358-1367 (2009).

17. T. Hananouchi, N. Sugano, T. Nishii, N. Nakamura, H. Miki, A. Kakimoto, M. Yamamura and H. Yoshikawa, "Effect of robotic milling on periprosthetic bone remodeling," J. Orthop. Res. 25(8), 1062-1069 (2007).

18. P. Kornprat, G. Werkgartner, H. Cerwenka, H. Bacher, A. El-Shabrawi, P. Rehak and H. J. Mischinger, "Prospective study comparing standard and robotically assisted laparoscopic cholecystectomy," Langenbecks Arch. Surg. 391(3), 14352443 (2006).

19. J. C. Wu, H. S. Wu, M. S. Lin, D. A. Chou and M. H. Huang, "Comparison of robot-assisted laparoscopic adrenalectomy with traditional laparoscopic adrenalectomy - 1 year followup," Surg. Endosc. 22(2), 463-466 (2008).

20. F. Rodriguez, S. Harris, M. Jakopec, A. Barrett, P. Gomes, J. Henckel, J. Cobb and B. Davies, "Robotic clinical trials of unicondylar arthroplasty," Int. J. Med. Robot 1(4), 20-28 (2005).

21. H. X. Zhou, Y. H. Guo, X. F. Yu, S. Y. Bao, J. L. Liu, Y. Zhang and Y. G. Ren, "Zeus robotassisted laparoscopic cholecystectomy in comparison with conventional laparoscopic cholecystectomy," Hepatobiliary Pancreat. Dis. Int. 5(1), 115-118 (2006).

22. T. R. K. Varma and P. Eldridge, "Use of the NeuroMate stereotactic robot in a frameless mode for functional neurosurgery," Int. J. Med. Robotics Comput. Assisted Surg. 2(2), 107-113 (2006).

23. K. S. Gurusamy, K. Samraj, G. Fusai and B. R. Davidson, Robot assistant for laparoscopic cholecystectomy. Cochrane Database of Systematic Reviews, Issue 1, (2009).

24. A. A. Wagner, I. M. Varkarakis, R. E. Link, W. Sullivan and L. M. Su, "Comparison of surgical performance during laparoscopic radical prostatectomy of two robotic camera holders, EndoAssist and AESOP: Apilot study," Urology 68(1), 70-74 (2006)

25. M. Alessandrini, A. De Padova, B. Napolitano, A. Camillo and E. Bruno, "The AESOP robot system for video-assisted rigid endoscopic laryngosurgery," Eur. Arch. Otorhinolaryngol. 265(9), 1121-1123 (2008).
26. N. Calcerrada Diaz-Santos, J. A. Blasco Amaro, G. A. Cardiel and E. Andradas Aragones, "The safety and efficacy of robotic image-guided radiosurgery system treatment for intra- and extracranial lesions: A systematic review of the literature," Radiother. Oncol. 89(3), 245-253 (2008).

27. D. W. Andrews, G. Bednarz, J. J. Evans and B. Downes, "A review of 3 current radiosurgery systems," Surg. Neurol. 66(6), 559-564 (2006).

28. F. Colombo, L. Casentini, C. Cavedon, P. Scalchi, S. Cora and P. Francescon, "Cyberknife radiosurgery for benign meningiomas: Short-term results in 199 patients," Neurosurgery 64(2 Suppl.), A7-13 (2009).

29. R. Berryhill, Jr., J. Jhaveri, R. Yadav, R. Leung, S. Rao, A. El-Hakim and A. Tewari, "Robotic prostatectomy: A review of outcomes compared with laparoscopic and open approaches," Urology 72(1), 15-23 (2008).

30. V. Ficarra, S. Cavalleri, G. Novara, M. Aragona and W. Artibani, "Evidence from robot-assisted laparoscopic radical prostatectomy: A systematic review," Eur. Urol. 51(1), 45-55; discussion 56 (2007).

31. S. Aiono, J. M. Gilbert, B. Soin, P. A. Finlay and A. Gordan, "Controlled trial of the introduction of a robotic camera assistant (EndoAssist) for laparoscopic cholecystectomy," Surg. Endosc. 16(9), 1267-1270 (2002).

32. J. M. Gilbert, "The EndoAssist robotic camera holder as an aid to the introduction of laparoscopic colorectal surgery," Ann. Roy. College Surgeons Engl. 91(5), 389-393 (2009).

33. K. Tanoue, T. Yasunaga, E. Kobayashi, S. Miyamoto, I. Sakuma, T. Dohi, K. Konishi, S. Yamaguchi, N. Kinjo, K. Takenaka, Y. Maehara and M. Hashizume, "Laparoscopic cholecystectomy using a newly developed laparoscope manipulator for 10 patients with cholelithiasis," Surg. Endosc. 20(5), 753-756 (2006).

34. I. Yoshino, T. Yasunaga, M. Hashizume and Y. Maehara, "A novel endoscope manipulator, Naviot, enables solo-surgery to be performed during video-assisted thoracic surgery," Interact. Cardiovasc. Thoracic Surg. 4(5), 404-405 (2005).

35. K. Yamada and S. Kato, "Robot-assisted thoracoscopic lung resection aimed at solo surgery for primary lung cancer," Gen. Thoracic Cardiovasc. Surg. 56(6), 292-294 (2008).

36. M. S. Eljamel, "Robotic neurological surgery applications: Accuracy and consistency or pure fantasy?" Stereotactic Funct. Neurosurg. 87(2), 88-93 (2009).

37. M. S. Eljamel, "Robotic application in epilepsy surgery," Int. J. Med. Robot 2(3), 233-237 (2006).

38. S. Nishihara, N. Sugano, T. Nishii, H. Miki, N. Nakamura and $\mathrm{H}$. Yoshikawa, "Comparison between hand rasping and robotic milling for stem implantation in cementless total hip arthroplasty," J. Arthroplasty 21(7), 957-966 (2006).

39. A. P. Schulz, K. Seide, C. Queitsch, A. von Haugwitz, J. Meiners, B. Kienast, M. Tarabolsi, M. Kammal and C. Jurgens, "Results of total hip replacement using the Robodoc surgical assistant system: Clinical outcome and evaluation of complications for 97 procedures," Int. J. Med. Robot 3(4), 301306 (2007).

40. M. Shoham, I. H. Lieberman, E. C. Benzel, D. Togawa, E. Zehavi, B. Zilberstein, M. Roffman, A. Bruskin, A. Fridlander, L. Joskowicz, S. Brink-Danan and N. Knoller, "Robotic assisted spinal surgery - From concept to clinical practice," Comput. Aided Surg. 12(2), 105-115 (2007).

41. I. Pechlivanis, G. Kiriyanthan, M. Engelhardt, M. Scholz, S. Lucke, A. Harders and K. Schmieder, "Percutaneous placement of pedicle screws in the lumbar spine using a bone mounted miniature robotic system: First experiences and accuracy of screw placement," Spine 34(4), 392-398 (2009).

42. P. Kornprat, G. Werkgartner, H. Cerwenka, H. Bacher, A. El-Shabrawi, P. Rehak and H. J. Mischinger, "Prospective study comparing standard and robotically assisted laparoscopic cholecystectomy," Langenbecks Arch. Surg. 391(3), 216-221 (2006). 
43. J. Heemskerk, R. Zandbergen, J. G. Maessen, J. W. Greve and N. D. Bouvy, "Advantages of advanced laparoscopic systems," Surg. Endosc. 20(5), 730-733 (2006).

44. H. G. Sim, S. K. H. Yip and C. W. S. Cheng, "Equipment and technology in surgical robotics," World J. Urol. 24(2), 128-135 (2006).

45. A. Rane, S. Kommu, B. Eddy, P. Rimington and C. Anderson, "Initial experience with the endoassist (R) camera holding robot in laparoscopic urological surgery," Eur. Urol. Suppl. 6(2), 186-186 (2007).

46. P. A. Finlay and P. Morgan, "PathFinder image guided robot for neurosurgery," Industr. Robot Int. J. 30(1), 30-34 (2003).

47. B. W. Fei, W. S. Ng, S. Chauhan and C. K. Kwoh, "The safety issues of medical robotics," Reliability Eng. Syst.Safety 73(2), 183-192 (2001).

48. P. Varley, "Techniques for development of safety-related software for surgical robots," IEEE Trans. Information Technol. Biomed. 3(4), 261-267 (1999).
49. J. Guiochet and A. Vilchis, "Safety analysis of a medical robot for tele-echography", Proceedings of the IARP Workshop on Dependable Robots, Toulouse, France (2002).

50. W. Korb, M. Kornfeld, W. Birkfellner, R. Boesecke, M. Figl, M. Fuerst, J. Kettenbach, A. Vogler, S. Hassfeld and G. Kornreif, "Risk analysis and safety assessment in surgical robotics: A case study on a biopsy robot," Minim. Invasive Ther. Allied Technol. 14(1), 23-31 (2005).

51. D. Kilic and E. A. Croft, "Safe planning for human-robot interaction," J. Robotic Syst. 22(7), 383-396 (2005).

52. C. D. Scales, Jr., P. J. Jones, E. L. Eisenstein, G. M. Preminger and D. M. Albala, "Local cost structures and the economics of robot assisted radical prostatectomy," J. Urol. 174(6), 2323 2329 (2005).

53. Y. Lotan, J. A. Cadeddu and M. T. Gettman, "The new economics of radical prostatectomy: Cost comparison of open, laparoscopic and robot assisted techniques," J. Urol. 172(4 Pt 1), 1431-1435 (2004).

\section{Appendix}

Robotic systems

\section{AESOP}

(Intuitive Surgical,

Sunnyvale, CA, USA)

Acrobot

(Acrobot Ltd, London, UK)

Cyberknife

(Accuray Inc., Sunnyvale, Ca, USA)

\section{da Vinci \\ (Intuitive Surgical, Sunnyvale, CA, USA)} EndoAssist (Prosurgics, High
Wycombe, UK)

\section{NeuroMate \\ (Renishaw Mayfield,} Gloucestershire, UK)

\section{Naviot \\ (Hitachi Hybrid Network Co. Ltd, Yokohama, Japan)}

PathFinder

(ProSurgics, High Wycombe, UK)
Purpose: Endoscopic manipulator.

System: Robot is fixed to the operating table. Present system is designed to be anthropomorphic to a human arm. Comprises four motorised joints, two passive joints and one manually adjusted joint to give 7 degrees of freedom (DOF). System was initially controlled by foot pedals but later modified to use voice control.

Purpose: Bone resection in knee joint surgery.

System: Consists of CT-based planner, a robot consisting of four-axis gross positioner and three-axis 'active constraint' robot with milling cutter. Surgeon guides the cutter. Robot 'actively constrains' the surgeon's motions to within a fixed envelope designated in the pre-operative planner.

Purpose: Used in stereotactic radiosurgery (SRS).

System: Consists of a six-joint, 6DOF robotic manipulator with a compact linear accelerator as end-effector. The manipulator is able to position the linear accelerator according to trajectory data provided by pre-operative plan. X-ray sources based in the floor and ceiling register pre-operative images and track the patient using the skull and spine. Surface fiducial markers and optical camera can also be used when target tracking is used, e.g. if treating the lung, breathing motion can be tracked, precluding the need for a complex gating system.

Purpose: Minimally invasive surgery.

System: Consists of two 10DOF manipulators, with the option of a third arm, able to hold a variety of tools, and an additional arm to hold the endoscope. The arms are mounted to a trolley and are able to be set to different heights by sliding along a $2-\mathrm{m}$ pole. The surgeon controls the robot from a workstation adjacent to the patient with stereoscopic vision.

Purpose: Endoscopic manipulator.

System: Consists of 4DOF, trolley-mounted, cylindrical geometry manipulator with an additional linkage to provide a remote centre of motion about the incision point. The laparoscope is attached to the robot by a pin joint and is free to rotate. It is controlled by the detected head movements of the surgeon.

Purpose: Frameless stereotactic surgery.

System: Consists of a 5DOF, electromechanical multi-joint arm that can be moved into a position in space. Feedback provided by potentiometers and incremental encoders on each axis. Uses ultrasonic registration system. Base plate is attached to the skull, with a four-spoke fiducial assembly, before imaging. The robot uses an ultrasound microphone array to detect fiducials and register to the pre-operative images.

Purpose: Endoscopic manipulator.

System: Consists of a 5-bar linkage mechanism and an optical zoom. Laparoscope attached near the insertion site with a holder with two degrees of angular freedom. Two active revolute joints at the base of the 5-bar linkage mechanism control the endoscope, moving it in the $x-y$ plane. The surgeon can manually set the range of motion of the manipulator by changing the length and direction of the links. An optical zoom function replaces the back and forth motion of the endoscope.

Purpose: Frameless stereotactic surgery.

System: Consists of a planning workstation and robot arm. Pre-operative images are fed to the planning workstation and the surgeon selects a point on images using the mouse. The arm consists of a 6DOF revolute manipulator mounted to a trolley. End-effector forms a guide/support for the surgeon to use. The robot uses a camera fixed to its end-effector, and fiducial markers stuck to the patient or screwed to the patient's skull, to register the pre-operative images to the patient. 


\section{ROBODOC}

(Novatrix Biomedical Inc., Sacramento, CA, USA)

\section{SpineAssist}

(Mazor Surgical

Technologies,

Ceasarea, Israel)

Zeus

(Intuitive Surgical, Sunnyvale, CA, USA)
Purpose: Bone resection.

System: Robot with a high-speed rotary cutter as its end-effector. Instrumented with a force sensor at the wrist. Requires a separate pre-operative planner 'OrthoDoc', which positions a model of the implant over the hip to calculate cutting volume.

Purpose: Pedicle screw placement in lumbar spinal fusion. Robot acts as a guide to the placement of the pedicle screws.

System: Consists of small drinks-can sized parallel manipulator and a planning station. Attached directly to the patient's spine and acts as a guide for tool positioning. Planning system registers intra-operative fluoroscopic images of the spine with pre-operative data. Planning system then instructs the surgeon to place the robot at the appropriate point on the clamp. The robot then moves to position a guide for the surgeon for precise drilling and pedicle screw insertion.

Purpose: Minimally invasive surgery

System: Consists of three robotic arms, one is the AESOP system which holds the camera, second and third are for surgical manipulation. Uses Microwirst at the end of arms to provide additional degrees of freedom. Surgeon controls through a console with video monitor. 